\title{
The Return Stroke of the Lightning Flash to Earth As a Source of VLF Atmospherics
}

\author{
A. S. Dennis and E. T. Pierce \\ Contribution From Stanford Research Institute \\ Menlo Park, Calif.
}

(Received October 21, 1963; revised February 18, 1964)

\begin{abstract}
The field radiated during the current surge at the source is derived by a new method. The effects of changing such parameters as rate of current rise and speed of channel development are indicated. Amplitude spectra at $100 \mathrm{~km}$ are deduced for typical first and subsequent strokes in a discharge carrying negative electricity to earth, and for a positive stroke. The three spectra peak at approximately 5,3 , and $3 \mathrm{kHz}$, respectively.

Mean amplitude spectra at $100 \mathrm{~km}$ are also deduced by extrapolation back, making allowances for propagation, of atmospheries observations. The average spectrum for a group of atmospherics obeys a simply normalized relation involving the frequency of maximum amplitude; this frequency changes between groups over the range of 4 to $7 \mathrm{kHz}$. The amplitudes, both on a broadband and a single-frequency basis, are log-normally distributed, with standard deviations of some $7 \mathrm{~dB}$.

Averaged spectra for groups of observations agree quite well with those computed from the stroke parameters. However, it is found that the spectral shape varies extensively among individual atmospheries.
\end{abstract}

\section{Introduction}

A companion paper [Arnold and Pierce, 1964] has surveyed the generation of VLF atmospherics during lightning flashes and has considered in detail the amplitude spectra associated with the $L$ pulses accompanying stepped leaders and with the $K$ changes occurring during certain stages of both cloud and ground discharges. The present paper examines the VLF atmospherics radiated during the return stroke of a flash to earth. These atmospherics represent the largest VLF disturbances associated with lightning but, as indicated in the companion paper, are not the sole VLF signals of importance. To a first approximation, a return stroke can be considered as a discharge in a vertical channel, growing upward from the ground to neutralize the charge deposited by the preceding leader. If the form of the current surge and the rate of growth of the channel are known, the spectrum of the resulting atmospheric can be estimated by applying Fourier methods to the second time derivative of the electric moment [Lejay, 1926]. The electric moment $M$ is usually defined as twice the summed product of the charges and their heights above ground, the factor two taking account of the image charges. The "current moment" is often used by radio engineers; it involves the product of current and the length over which the current flows, and is approximately equal to $d M / d t$.

\section{Theoretical Approach}

\subsection{Background}

As the treatment of return strokes by Bruce and Golde [1941] summarized rather well the observations made up to that time, and as their model for a return stroke has been widely accepted, a brief description is desirable before modifications, in the light of more recent work, are discussed. Bruce and Golde considered the current surge at the ground to be of the double-exponential form

$$
i_{t}=i_{0}[\exp (-\alpha t)-\exp (-\beta t)]
$$

where $i_{t}$ is the current at the base of the return stroke at time $t$, and $i_{0}, \alpha$, and $\beta$ are constants. They suggested as typical values $30,000 \mathrm{~A}, 4.4 \times 10^{4}$ $\sec ^{-1}$, and $4.6 \times 10^{5} \mathrm{sec}^{-1}$ for $i_{0}, \alpha$, and $\beta$, respectively. From photographic data, notably that of Schonland [1956], Bruce and Golde concluded that the first return stroke of a flash to ground grows upward at a rate given by

$$
V_{t}=V_{0} \exp (-\gamma t)
$$

where $V_{0}$ is $8 \times 10^{7} \mathrm{~m} \mathrm{sec}^{-1}$ and $\gamma$ is $3 \times 10^{4} \mathrm{sec}^{-1}$. For subsequent strokes in a lightning flash, the upward growth is relatively constant, so that $\gamma$ is equal to 0 [Schonland, 1956]. 
Bruce and Golde give a simple treatment of their return-stroke model in which it is assumed that the current in the channel is uniform. This requires the instantaneous transfer of charge from the base of the stroke to the tip. Hence

$$
\begin{aligned}
\frac{d M}{d t}=2 i_{t} \int_{0}^{t} V_{t} d t= & \frac{2 i_{0} V_{0}}{\gamma}[\exp (-\alpha t) \\
& -\exp (-\beta t)][1-\exp (-\gamma t)],
\end{aligned}
$$

where $M$ is the dipole moment. (The factor 2 allows for image charges.) [Lejay, 1926.] Equation (2.3) can be differentiated with respect to time and then treated by Fourier methods to obtain the source spectrum for both first and subsequent strokes. The resulting spectra peak near $9 \mathrm{kHz}$ for first strokes and $7 \mathrm{kHz}$ for subsequent strokes [Pierce, 1960].

\subsection{A Modified Treatment}

A wide range of spectra can be generated by varying the Bruce-Golde parameters for return strokes. Furthermore, additional degrees of freedom can be introduced by abandoning the assumption of uniform current in the channel, by permitting variations in the charge laid down per unit length by the leader stroke, and so on. The additional degrees of freedom greatly complicate the derivation of the source spectrum. As the spectrum of an individual stroke is influenced by such things as nonvertical sections of channel, branching, and irregularities of the current surge, which cannot be satisfactorily included in any simple returnstroke model, a point is soon reached beyond which further elaboration of models is of little practical value.

The following treatment avoids the unrealistic assumption of a uniform current and, hence, instantaneous charge transfer, in the lightning channel. Consider a first return stroke, described by (2.1) and (2.2), with the charge in the channel moving at a constant velocity $u$, where $u \geq V_{0}$. If $h_{t}$ is the channel length at time $t$, obviously

$$
h_{t}=\int_{0}^{t} V_{t} d t
$$

The charge arriving at the tip is "frozen" there to neutralize charge of opposite sign laid down by the leader stroke. Thus, at any time $t$, the channel will contain a flowing charge of density $\rho$ per unit length and be surrounded by a frozen charge of density $\rho^{\prime}$ per unit length. The quantity $\rho$ is a function of height, $h$, and time, $t$; it is given by

$\rho=\frac{i_{0}}{u}\left\{\exp \left[-\alpha\left(t-\frac{h}{u}\right)\right]-\exp \left[-\beta\left(t-\frac{h}{u}\right)\right]\right\}$.

Let $\rho_{t}$ be the density of flowing charge at the tip. Then the charge laid down at the tip per unit time is $\rho_{t}\left(u-V_{t}\right)$, and the density laid down per unit length is

where

$$
\rho_{t}^{\prime}=\rho_{t}\left[\frac{u-V_{t}}{V_{t}}\right]
$$

$$
\rho_{t}=\frac{i_{0}}{u}\left\{\exp \left[-\alpha\left(t-\frac{h_{t}}{u}\right)\right]-\exp \left[-\beta\left(t-\frac{h_{t}}{u}\right)\right]\right\} .
$$

The electric moment at time $t, M_{t}$, is given by

$$
M_{t}=2 \int_{0}^{h_{t}}\left(\rho+\rho^{\prime}\right) h \cdot d h,
$$

where the factor 2 allows for image charges. By standard methods for differentiating definite integrals, and recognizing that $\rho^{1}$ does not depend on $t$,

$$
\frac{d M_{t}}{d t}=2 \int_{0}^{h_{t}} \frac{\partial \rho}{\partial t} h \cdot d h+2 \int_{0}^{h_{t}} \rho \cdot \frac{\partial h}{\partial t} \cdot d h+2\left(\rho_{t}+\rho_{t}^{\prime}\right) h_{t} \frac{d h_{t}}{d t} .
$$

As $h$ is not a function of $t$, the second term on the right is zero. Differentiating (2.4) and (2.5) and substituting into (2.8) lead, after some manipulation, to

$$
\begin{aligned}
\frac{d M_{t}}{d t}=\frac{2 i_{0} u}{\alpha} & \exp (-\alpha t) \cdot\left[\exp \left(\frac{\alpha h_{t}}{u}\right)-1\right] \\
& -\frac{2 i_{0} u}{\beta} \exp (-\beta t)\left[\exp \left(\frac{\beta h_{t}}{u}\right)-1\right]
\end{aligned}
$$

Differentiating again with respect to time yields

$$
\begin{aligned}
& \frac{d^{2} M}{d t^{2}}=2 i_{0} u \exp (-\alpha t)\left[1-\exp \left(\frac{\alpha h_{t}}{u}\right)\right] \\
& +2 i_{0} V_{0} \exp (-\gamma t) \exp \left[-\alpha\left(t-\frac{h_{t}}{u}\right)\right] \\
& -2 i_{0} u \exp (-\beta t)\left[1-\exp \left(\frac{\beta h_{t}}{u}\right)\right] \\
& -2 i_{0} V_{0} \exp (-\gamma t) \exp \left[-\beta\left(t-\frac{h_{t}}{u}\right)\right]
\end{aligned}
$$

It is seen that, for $u$ equal to $\infty,(2.9)$ becomes identical with the Bruce-Golde expression for $d M_{t} / d t$, as would be expected.

\subsection{Influence of the Various Parameters on Return- Stroke Spectra}

In order to study the effects of varying the parameters in (2.10), two computer programs have been set up. The first provides $d^{2} M / d t^{2}$ at intervals of $1,2,3 \ldots 100 \mu \mathrm{sec}$; the second computes $d^{2} M / d t^{2}$ at intervals of $2,4,6 \ldots 1000 \mu \mathrm{sec}$, and then uses this output to derive the Fourier coefficients at frequencies of $1,2,3 \ldots 25 \mathrm{kHz}$. By inserting some 50 
combinations of the parameters into the program, the effects of changes in the individual ones have been determined. Results have been normalized to show electric field components at $100 \mathrm{~km}$ from the source.

Figures 1 and 2 show the effects of changing $u$ from $\infty$ to a finite value. Curve (a) of figure 1 shows $d^{2} M / d t^{2}$ as a function of time, $t$, for a first return stroke with the following parameters: $\alpha=$ $4.5 \times 10^{4} \mathrm{sec}^{-1}, \quad \beta=4.5 \times 10^{5} \mathrm{sec}^{-1}, \gamma=3 \times 10^{4} \mathrm{sec}^{-1}$, $V_{0}=8 \times 10^{7} \mathrm{~m} / \mathrm{sec}^{-1}, i_{0}=30,000 \mathrm{~A}$, and $u=\infty$. Apart from very minor changes in $\alpha$ and $\beta$, this is the BruceGolde first return stroke, with a maximum current near 20,000 A. Curves (b) and (c) of figure 1 show $d^{2} M / d t^{2}$ with $u$ reduced to $3 \times 10^{8} \mathrm{~m} / \mathrm{sec}^{-1}$ and $8 \times 10^{7}$ $\mathrm{m} / \mathrm{sec}^{-1}$, respectively, with all other parameter sunchanged. The speeds chosen, that of light and of $V_{0}$, represent upper and lower limits for $u$. Curve (a) shows a positive peak near $3 \mu$ sec and the maximum negative excursion at $35 \mu$ sec. Little change is evident on curve (b), apart from a slight delay of the negative excursion. However, reduction of $u$ to $8 \times 10^{7} \mathrm{~m} / \mathrm{sec}^{-1}$ (curve (c)) moves the positive peak to $5 \mu$ sec and the greatest negative excursion to 43 usec. Curves (a), (b), and (c) of figure 2 show the corresponding spectra; the spectral peak $\left(f_{m}\right)$ moves from $9.5 \mathrm{kHz}$ for $u=\infty$ to $9 \mathrm{kHz}$ for $u=$ $3 \times 10^{8} \mathrm{~m} / \mathrm{sec}^{-1}$, and to $8 \mathrm{kHz}$ for $u=8 \times 10^{7} \mathrm{~m} / \mathrm{sec}^{-1}$.

The maximum length attained by a first stroke channel is given by $V_{0} / \gamma$. The Bruce-Golde stroke has a maximum length of only $2.7 \mathrm{~km}$, which seems low for some parts of the world. It would appear that lengthening the channel would lead to a lower value for $f_{m}$. The lengthening has been done in the computer program by reducing $\gamma$ to $2 \times 10^{4} \mathrm{sec}^{-1}$, which leads to a total length of $4 \mathrm{~km}$, and by using all other parameters from curve (b) of figure 1 . Figure 3 shows $d^{2} M / d t^{2}$ for the lengthened stroke as curve (a): Curve (b) $\left(\gamma=3 \times 10^{4} \mathrm{sec}^{-1}\right)$ is reproduced from figure 1 for comparison. The change in $\gamma$ exerts little effect upon the positive peak, but the negative excursion is delayed in its maximum by about $5 \mu$ sec. The corresponding spectra are shown in figure 4 . The spectral peak, $f_{m}$, is lowered by about $1 \mathrm{kHz}$ by the change in $\gamma$.

The effect of variations of $\alpha$ and $\beta$ must be considered simultaneously. A large number of spectra have been derived for strokes with $\gamma=3 \times 10^{4} \mathrm{sec}^{-1}$, $u=3 \times 10^{8} \mathrm{~m} / \mathrm{sec}^{-1}$, and $V_{0}=8 \times 10^{7} \mathrm{~m} / \mathrm{sec}^{-1}$, and various combinations of $\alpha$ and $\beta$. Figure 5 shows $f_{m}$ as a function of $\alpha$ and $k$, where $k=\beta / \alpha$. It is seen that for large $k$, which corresponds to very short rise times for the current surge, $f_{m}$ is determined almost entirely by $\alpha$, that is, by the rate of decay of the current waveform.

\subsection{Return-Stroke Spectra Deduced From Current Measurements}

The various methods of measuring the current surges in return strokes have been described by Wagner and McCann [1950]. They include klydonographs, fusible wires, magnetic surge-crest ammeters, magnetic surge-front recorders, fulchronographs, and cathode-ray oscillographs. Care must be used in interpreting the data presented. For example, the magnetic link records give the maximum currents in flashes rather than in individual strokes.

A review of data on return-stroke current waveforms suggests that Berger's [1961, 1962] measurements using a high-speed oscilloscope are of special merit. It appears that many previously reported values of rise times are in error because of instrumental lag. This is especially true for subsequent strokes, which Berger has found to peak in roughly 1 $\mu$ sec. For a first return stroke, transferring negative charge to earth, the observational data suggests the parameter values, $\alpha=2 \times 10^{4} \mathrm{sec}^{-1}, \beta=2 \times 10^{5} \mathrm{sec}^{-1}$, and $i_{0}=30,000 \mathrm{~A}$. Curve (a) of figure 6 shows $d^{2} M / d t^{2}$ for such a stroke, with $\gamma=3 \times 10^{4} \mathrm{sec}^{-1}$, $V_{0}=8 \times 10^{7} \mathrm{~m} / \mathrm{sec}^{-1}$, and $u=3 \times 10^{8} \mathrm{~m} / \mathrm{sec}^{-1}$.

For subsequent strokes, the observations indicate that $\alpha$ equals $1.4 \times 10^{4} \mathrm{sec}^{-1}, \beta$ is at $6 \times 10^{6} \mathrm{sec}^{-1}$, and $i_{0}$ is $10,000 \mathrm{~A}$. For this case, $k(\beta / \alpha)$ is near 400 , and so $\beta$ exerts little influence upon the VLF spectrum. Accordingly, (2.10) can be simplified by setting $\beta$ equal to $\infty$. Curve (b) of figure 6 shows $d^{2} M / d t^{2}$ for this subsequent return stroke, with $V_{0}$ and $u$ as for the first return stroke and $\gamma$ equal to 0 . The latter condition implies an infinite upward growth rate of the channel, but the error is not serious. By the time the length of the "model" channel surpasses the actual one, the current has already become very small.

Flashes to earth bringing down positive charge are rare; they represent perhaps only 5 percent of the total number of discharges to ground. Berger [1962] reports that the strokes carrying positive charge to earth usually take about $30 \mu$ sec to peak and that the maximum current is of the order of $5,000 \mathrm{~A}$. It seems that appropriate parameters would be $i_{0}=7,000 \mathrm{~A}, \alpha=8 \times 10^{3} \mathrm{sec}^{-1}$, and $\beta=8 \times 10^{4}$ $\sec ^{-1}$, while for lack of better data the values of $V_{0}$, $\gamma$, and $u$ used in the inst stroke (negative) will be retained. The plot of $d^{2} M / d t^{2}$ for this stroke is shown as curve (c) of figure 6 .

The spectra of the typical return strokes just described are shown in figure 7 , where curves (a), (b), and (c) correspond to those of figure 6 . It is seen that the peaks occur near 5,3 , and $3 \mathrm{kHz}$, respectively.

Some writers have extended the Bruce-Golde model to include a third and even fourth exponential term, writing the expression for the return-stroke current as $i_{t}=i_{0}[a \exp (-\alpha t)-b \exp (-\beta t)+d \exp$ $(-\delta t)+e \exp (-\epsilon t)]$ [Barlow et al., 1954; Williams, 1959]. Such expressions can be used to include the weak currents which sometimes persist for several milliseconds in lightning channels. Examination of oscillograms showing such currents reveals a tendency for them to be rather flat, with irregular surges (the $M$ changes) distributed in a random fashion. They do not fit the exponential model, as a rule, and any attempt to iind typical values of $\delta$ and $\epsilon$ does not appear to have much chance of success. The long continuing components are significant in the generation of ELF radiation (slow tails) rather than VLF radiation. 


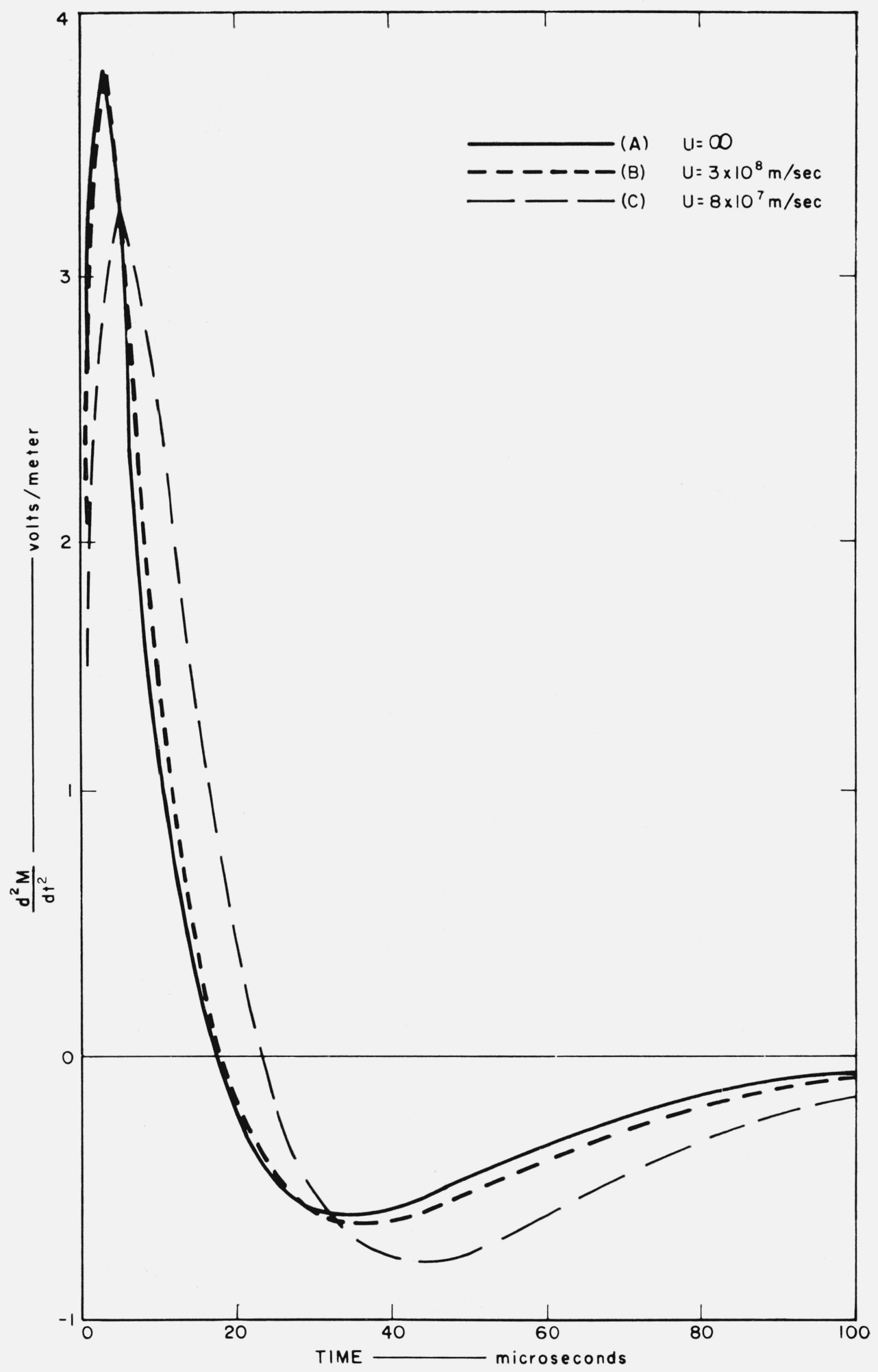

Figure 1. Curves of $\mathrm{d}^{2} \mathrm{M} / \mathrm{dt}^{2}$ versus time at $100 \mathrm{~km}$, showing effect of varying $\mathrm{u}$. 


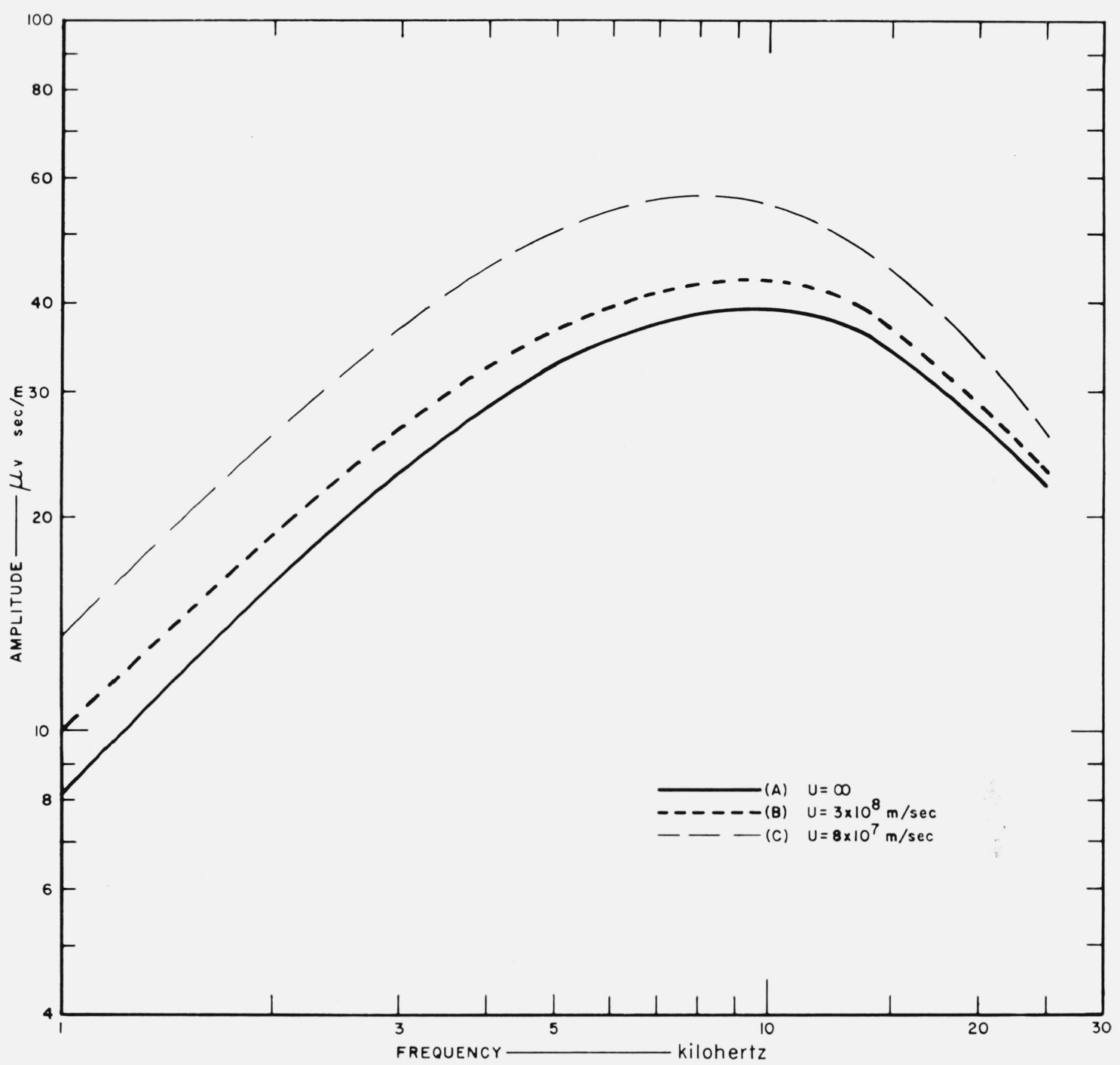

FIGURE 2. Return-stroke amplitude spectra at $100 \mathrm{~km}$, showing effect of varying $\mathrm{u}$.

\section{Observations of Return-Stroke Atmospherics}

The preceding section has shown how the source amplitude spectrum of the VLF atmospheric generated during a return stroke may be derived by combining theory and the experimental measurements of current surges. Many researchers have also deduced amplitude spectra at the source by observing atmospherics. Since the atmospherics are usually recorded at a considerable distance from the originating lightning discharge, it is necessary to apply an appreciable correction for the modifications to the spectrum introduced during propagation, if extrapolation back to source conditions is to be reliable.

\subsection{The Mean Amplitude Spectrum}

An examination has been made of the average amplitude spectrum as deduced from several researches. These include the work of the group at King's College, London, England [Chapman and Matthews, 1953; Edwards, 1956; and Steptoe, 1958] and other British papers [Horner, 1961; Croom, 1961] and three American contributions [Watt and Maxwell, 1957; Taylor and Jean, 1959; Taylor, 1963]. Altogether, 11 average curves were considered. When these data are examined, after normalization to a distance of $100 \mathrm{~km}$, it is found that the King's College results tend to be greater in amplitude than those of other workers. It is believed that this is due to the selection of the larger 


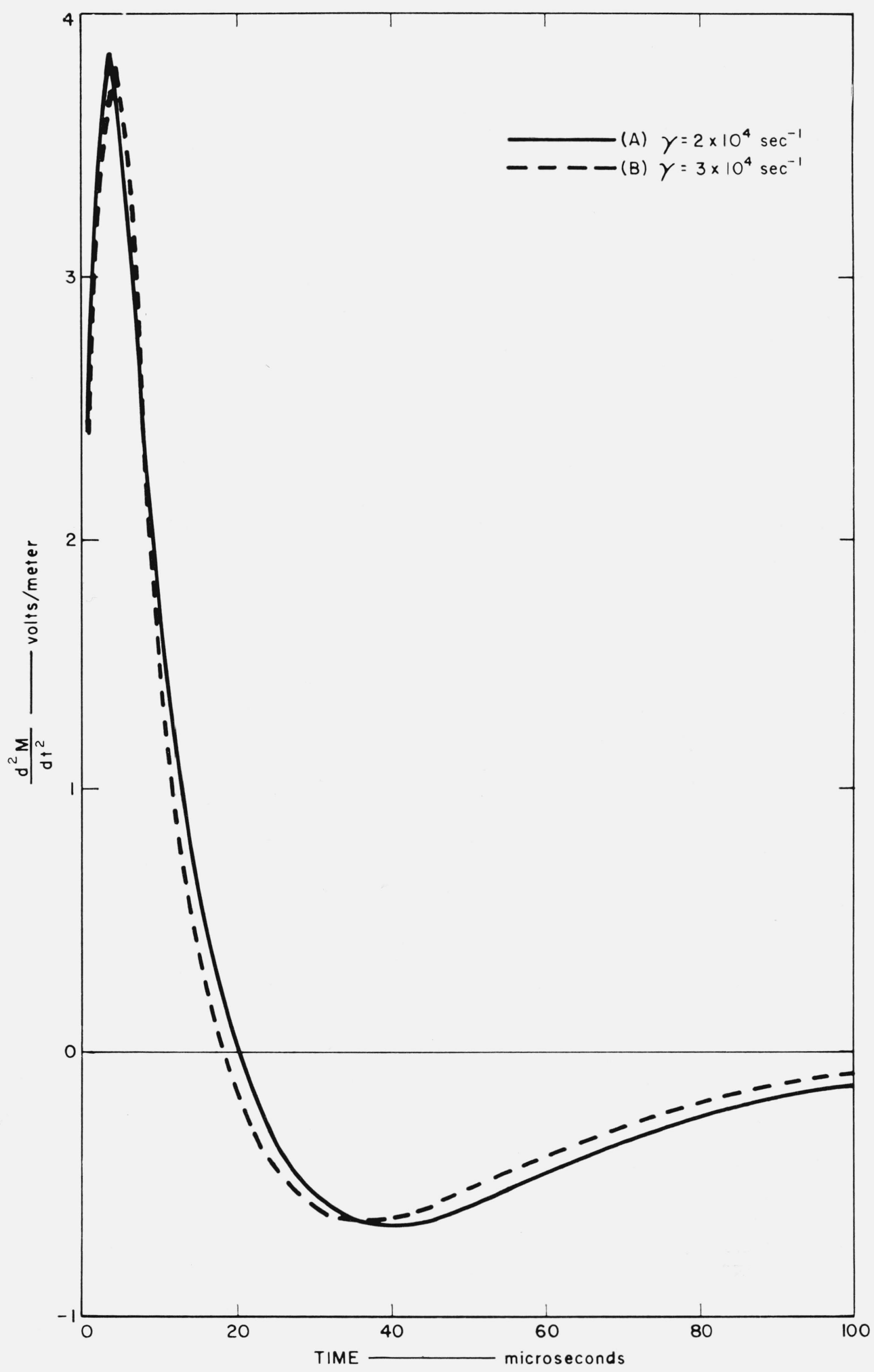

Figure 3. Curves of $\mathrm{d}^{2} \mathrm{M} / \mathrm{dt}^{2}$ versus time at $100 \mathrm{~km}$, showing effect of varying $\gamma$. 


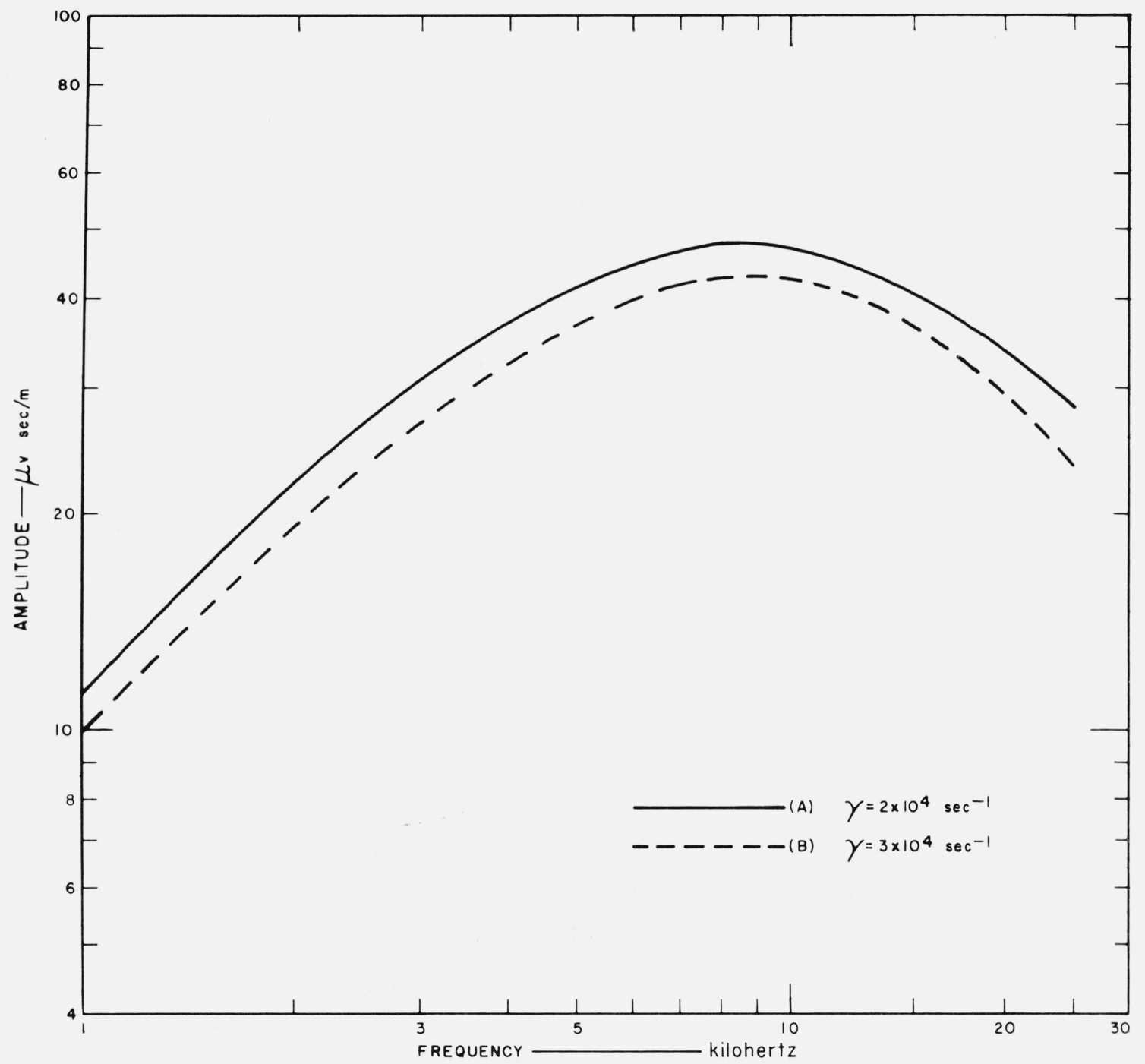

FIGURE 4. Return-stroke amplitude spectra at $100 \mathrm{~km}$, showing effect of varying $\gamma$.

783 


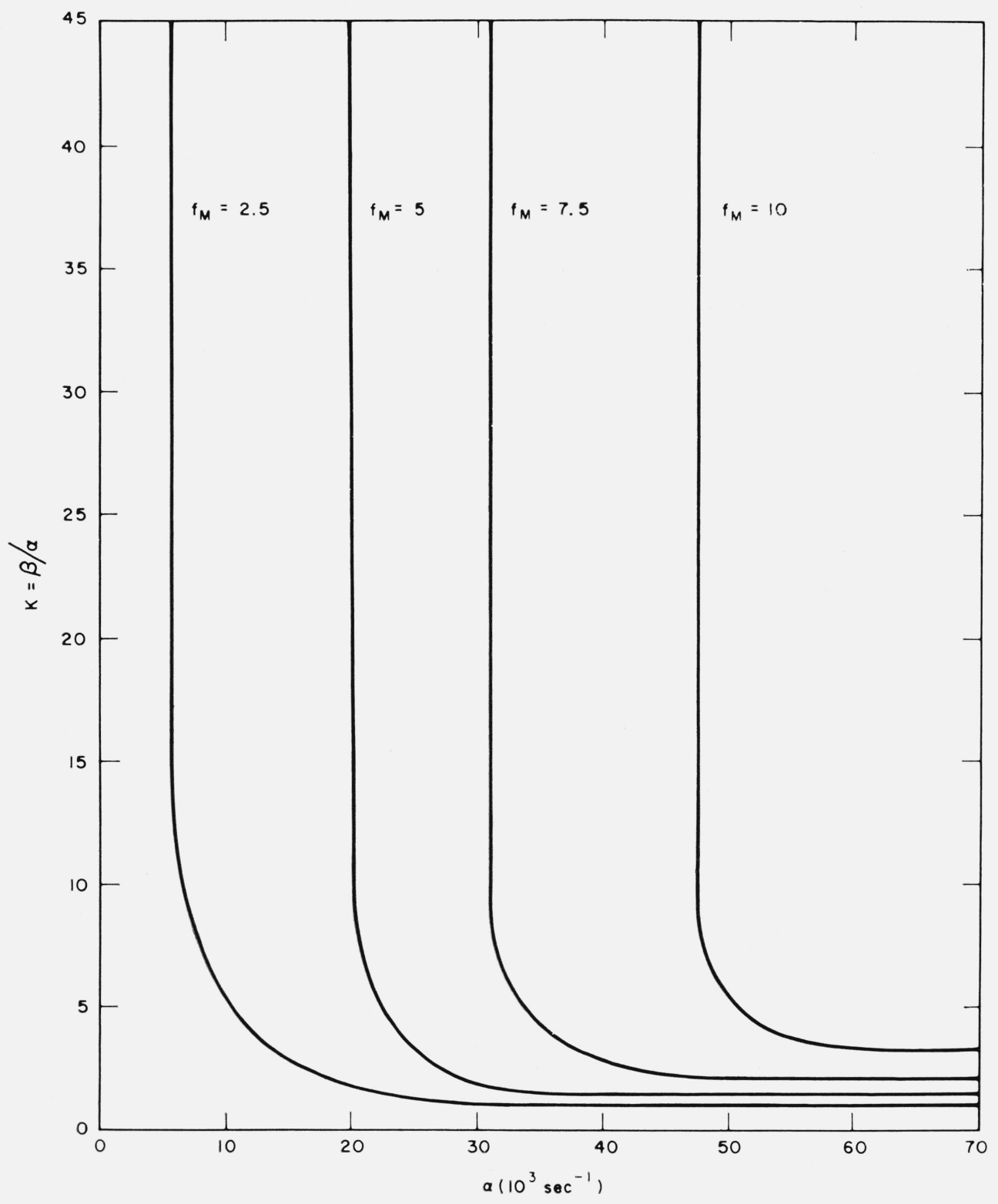

Figure 5. Variation of $\mathrm{f}_{\mathrm{m}}$ with $a$ and $\beta$.

atmospherics by triggering methods in an area of high background noise, and by an effective reliance upon a triggering system (the British CRDF network) for the location of the sources of the atmospherics. The observations of Horner [1961], in which the amplitudes at $6 \mathrm{kHz}$ of all atmospherics originating in a local storm were recorded, are probably by far the most reliable guide to the mean amplitude.

Curve (a) on figure 8 shows the average derived from the experimental data considered. The plot is normalized in terms of $E / E_{m}$ and $f / f_{m}$ where $E$ is the field in $\mu \mathrm{Vsec} / \mathrm{m}$ and $f$ the frequency. The frequency $f_{m}$ is that at which the peak value of field, $E_{m}$, is attained. Also represented on figure 8 are the two equations

$$
\log \left(E / E_{m}\right)=-\left|\log f / f_{m}\right|
$$

and

$$
\log \left(E / E_{m}\right)=-(0.8)\left|\log f / f_{m}\right| .
$$

The value of $f_{m}$ lies between 3 and $7 \mathrm{kHz}$ for the various groups of experimental results with $5 \mathrm{kHz}$ being a good average; at $100 \mathrm{~km}, E_{m}$ may be estimated as $50 \mu \mathrm{Vsec} / \mathrm{m}$, the greatest reliance for the amplitude information being placed on Horner's [1961] work. Scales corresponding to $f_{m}=5 \mathrm{kHz}$ 


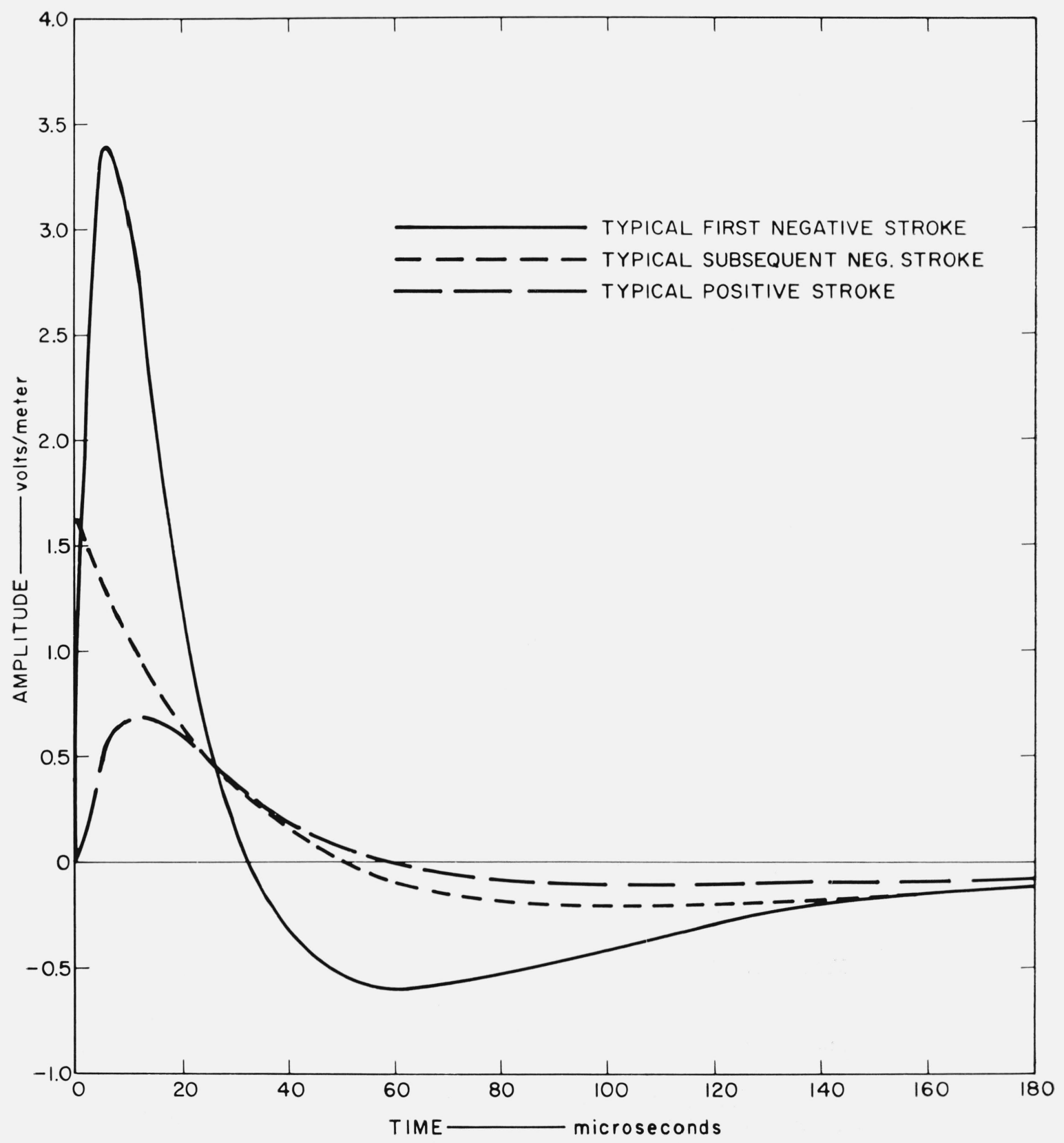

FiguRE 6. Curves of $\mathrm{d}^{2} \mathrm{M} / \mathrm{dt}^{2}$ versus time at $100 \mathrm{~km}$ for typical return strokes. 


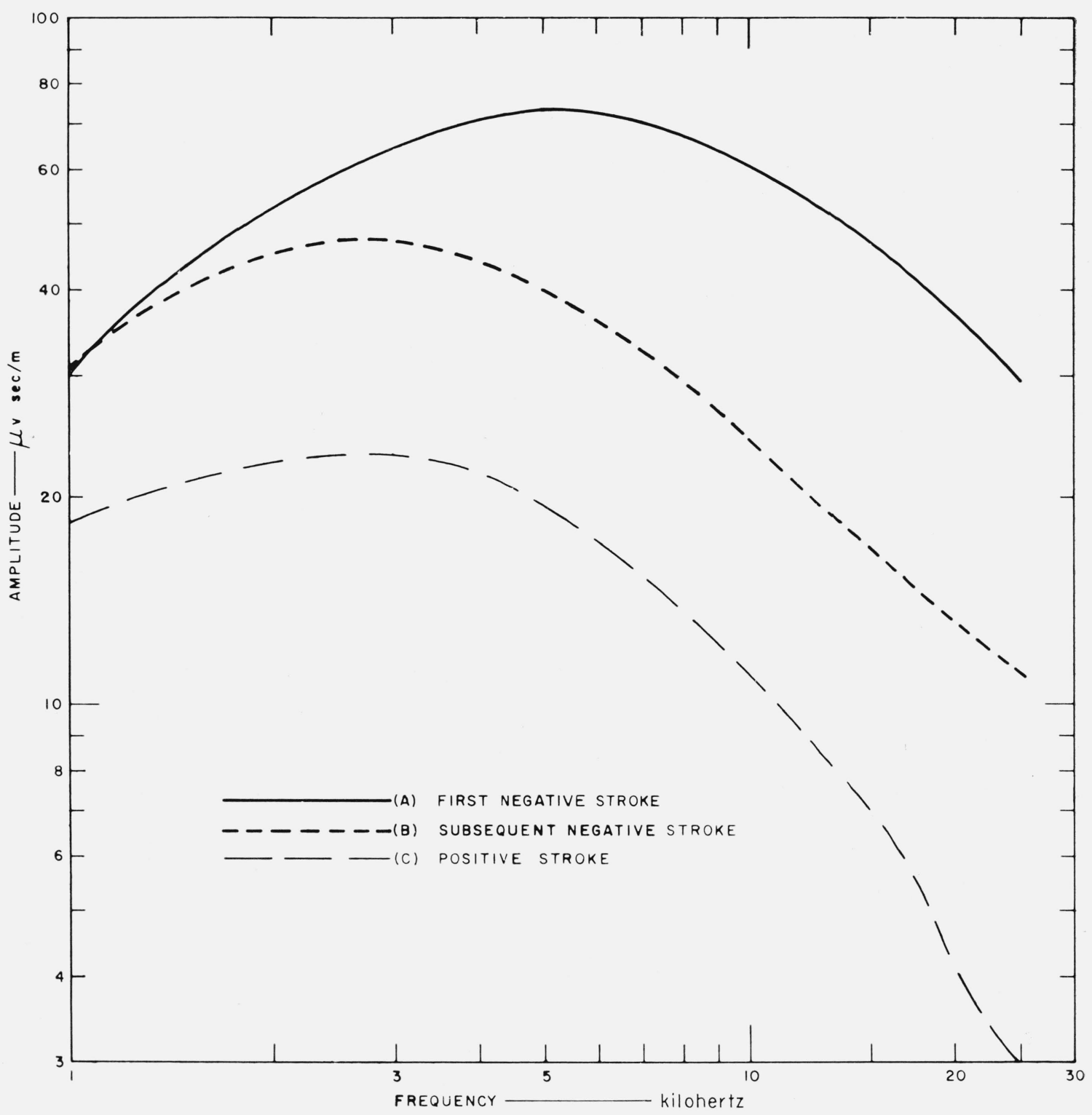

FiguRe 7. Amplitude spectra at $100 \mathrm{~km}$ for typical return strokes.

and $E_{m}=50 \mu \mathrm{Vsec} / \mathrm{m}$ are included on figure 8 . Over the limited frequency range of 2 to $20 \mathrm{kHz}$, (3.2) fits most of the experimental results reasonably well. Perhaps the worst agreement is with the data of Tavlor and Jean [1959] for which the curve of $E / E_{m}$ against frequency is much broader than is indicated by (3.2); the Taylor-Jean measurements also give the highest value, $7 \mathrm{kHz}$, for $f_{m}$. This latter result is perhaps not unexpected, since the Taylor-Jean data included many mountain storms for which there is reason to believe the channels are short and $\gamma$ is large; hence (sec. 2.3) $f_{m}$ is high. It is interesting to note that Taylor's [1963] most recent experimental data, obtained in the Texas-Oklahoma area and therefore uncontaminated by mountain storms, give $f_{m}$ for return-stroke atmospherics as averaging 5 $\mathrm{kHz}$. This is in excellent agreement with the general conclusions above.

\subsection{Amplitude Variations}

Variations in amplitude, generated at the source, may be observed upon a broadband or narrowband basis. If the source spectra of all atmospherics were the same, which is obviously an unrealistic postulation, identical results for amplitude distribution would be obtained by the two approaches. Valuable results regarding source amplitude variations are best obtained under two sets of circumstances. First, a close storm may be studied; in this instance 


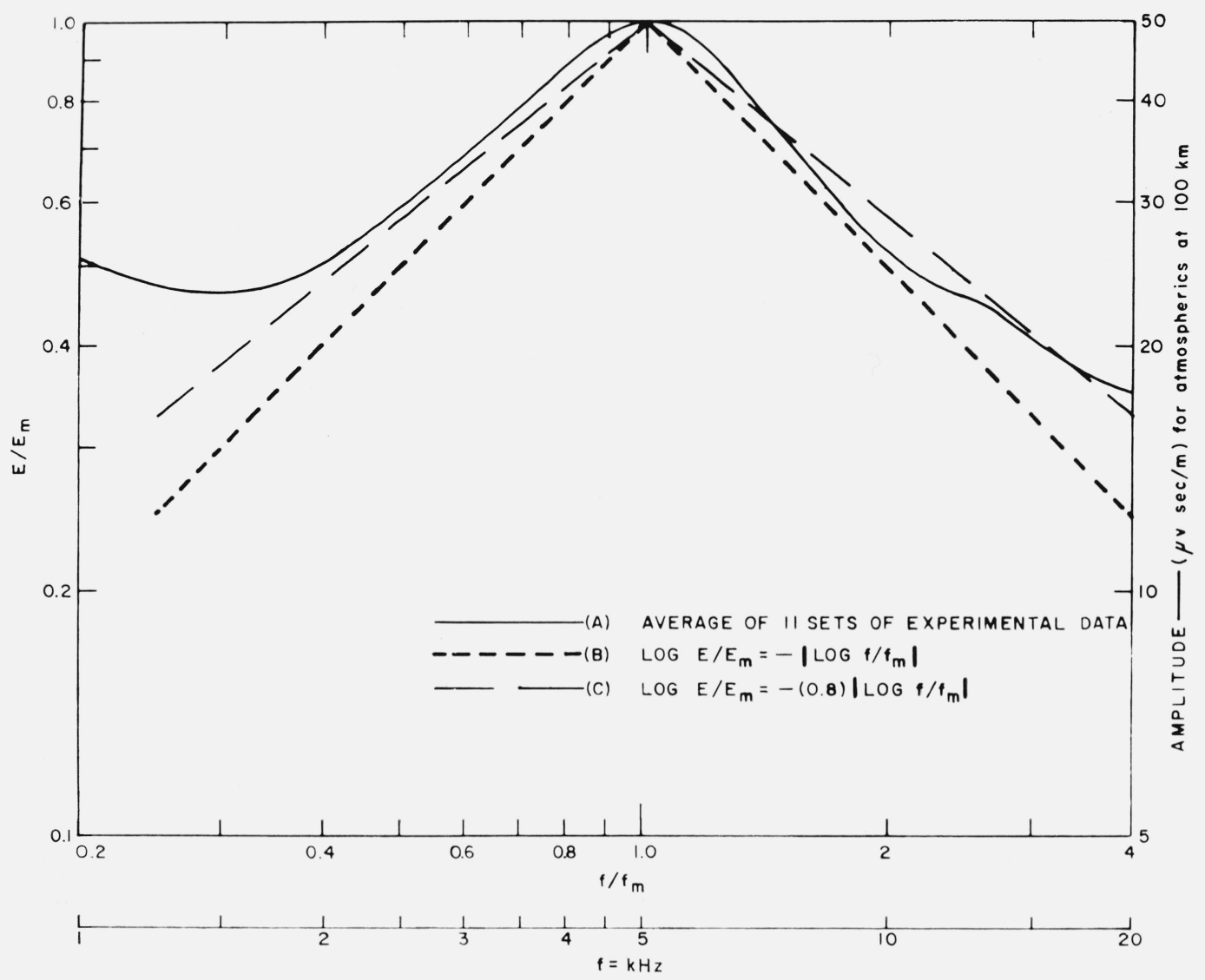

FiguRE 8. Normalization of average spectrum for return-stroke atmospherics.

propagation effects are negligible. Second, atmospheries from an isolated distant storm may be recorded over a period during which propagation conditions are stable.

An examination of several samples of data shows that in all cases the amplitude variability is well represented by a log-normal distribution. If $E_{\text {med }}$ is the median amplitude and the size $E$ of the individual atmospherics is expressed in decibels relative to $E_{\text {med }}$, then $P$, the percentage exceeding $E_{p}$, is given by

$$
P=\frac{100}{\sigma \sqrt{2 \pi}} \int_{E_{p}}^{\infty} \exp -\left(\frac{E-E_{\mathrm{med}}}{2 \sigma^{2}}\right)^{2} d E,
$$

where $\sigma$ is the standard deviation in decibels. On probability paper, the relation between $P$ and $E$ is a straight line with a slope of $\sigma$. The log-normal distribution is, of course, that expected where a number of contributing factors of independent variability enter into a problem.

A typical sample of observations is plotted on fig. 9. These are for the peak-to-peak amplitude of radiation fields from a storm at a distance of $60 \mathrm{~km}$ [Pierce, 1950]. A straight line, corresponding to the log-normal distribution, fits the results quite well, the slope being $8.6 \mathrm{~dB}$. Other information that has been examined also gives log-normal variations. Among these data are the $10-\mathrm{kHz}$ observa- tions of Chapman [1955] $(\sigma=6.7 \mathrm{~dB})$ and the 10.5$\mathrm{kHz}$ measurements of Hefley, Doherty, and Linfield [1959] $(\sigma=4.0$ and $6.3 \mathrm{~dB})$. Although the radiated atmospheric is proportional to $d^{2} M / d t^{2}$, where $M$ is the electric moment and $t$ the time, and should therefore not necessarily have the same amplitude distribution as variations in current or $M$, it is perhaps worth noting that the peak current magnitudes listed by Bruce and Golde [1941] fit a lognormal distribution with $\sigma=8.5 \mathrm{~dB}$. Furthermore, two samples of data given by Pierce [1950] for the change in $M$ associated with a return stroke also follow the log-normal distribution, with standard deviations of $6.5 \mathrm{~dB}$ and $9.5 \mathrm{~dB}$. All these results are in reasonable agreement with the conclusion of Horner [1960] that the amplitude variations of return-stroke atmospherics at the source obey a log-normal law with a standard deviation of some $7 \mathrm{~dB}$.

\subsection{Spectral Variations}

It has been tacitly suggested in the preceding two sections that the shape of the amplitude spectrum is defined by (3.2), that spectral fluctuations are taken account of by changes in $f_{m}$, and that amplitude variations apply similarly at all frequencies with an overall multiplying factor $B$ that follows 


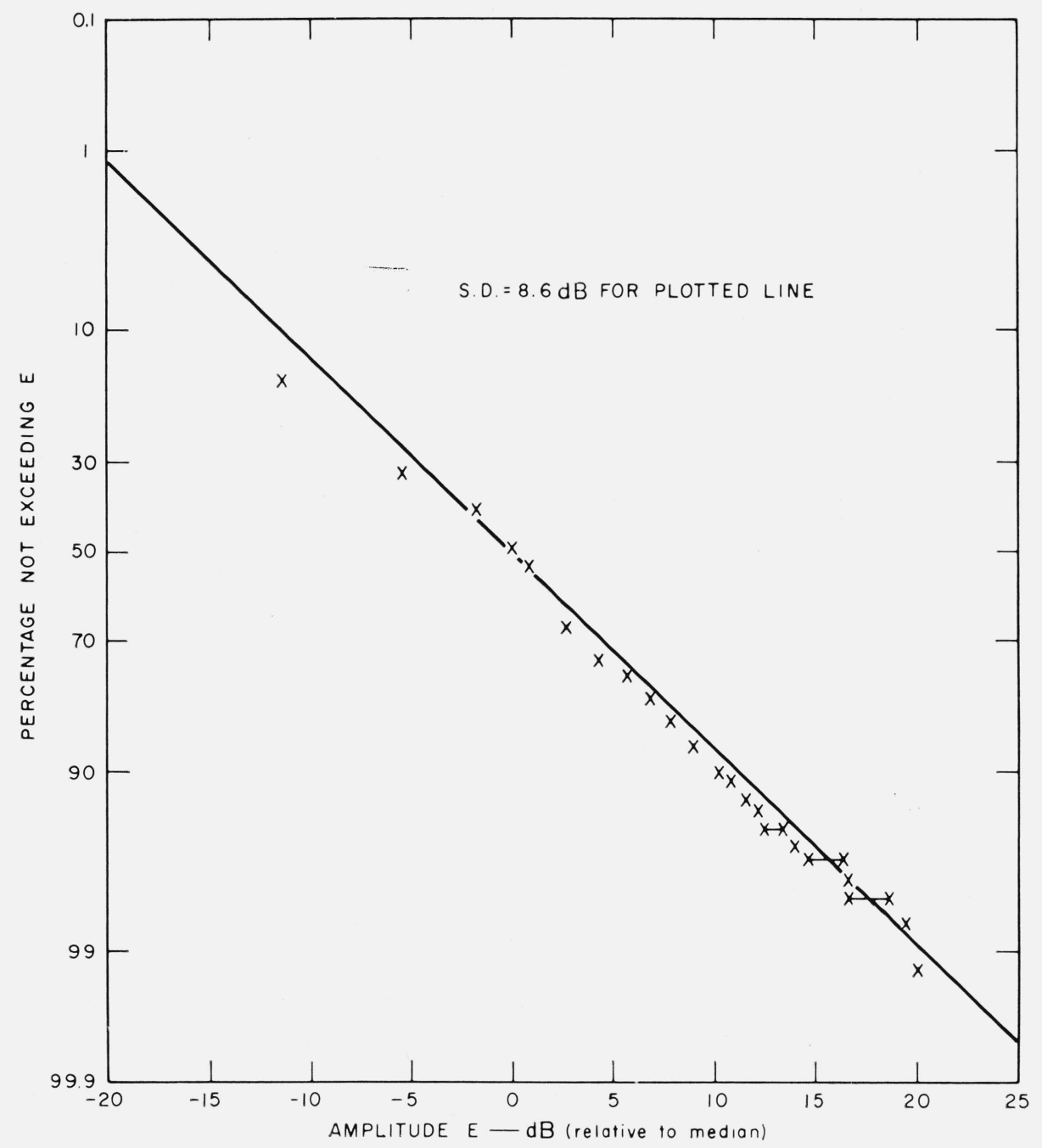

Figure 9. Amplitude distribution for peak-to-peak radiation fields at $60 \mathrm{~km}$.

a log-normal distribution. Equation (3.2) can be modified to the form

$E=B E_{m}$ antilog $\left\{-(0.8)|\log f| f_{m} \mid\right\} \cdot$

It follows that if amplitudes are being compared at two frequencies, $f_{1}$ and $f_{2}$, both exceeding $f_{m}$, then the ratio $E_{f_{1}} / E_{f 2}$ is independent of both $f_{m}$ and $B$, and apparently invariant for two given frequencies. If, however, a sample of atmospherics is examined in this manner, the ratios are not found to be constant but to follow a distribution that again approximates a log-normal law.

Figure 10 shows an illustrative sample. The data are those of Chapman [1955], the ratios of amplitudes at 18 and $10 \mathrm{kHz}$ being recorded for atmospherics propagated over the same distance with similar ground and ionospheric conditions.
The log-normal distribution is followed, with $\sigma=5.2$ dB. The results of Bowe [1951] also fit similar distributions, although the condition of $f_{1}$ and $f_{2}$ being greater than $f_{m}$ is hardly satisfied for Bowe's samples. At 4.25 and $7.5 \mathrm{kHz}, \sigma=6.2 \mathrm{~dB}$; at 3.5 and $7.5 \mathrm{kHz}$, two samples yield $\sigma=4.8 \mathrm{~dB}$ and $\sigma=5.2$ $\mathrm{dB}$.

The apparent discrepancy between the observed fluctuations in the ratio of amplitudes at two frequencies and the constancy predicted by (3.2) is essentially due to the deficiencies of (3.2). Although it is perhaps the best simple formulation of the mean spectrum for a group of atmospherics, and the differences in the mean between groups may be represented by adjusting $f_{m}$, it is quite incorrect to consider that (3.2) should fit all individual atmospherics. 


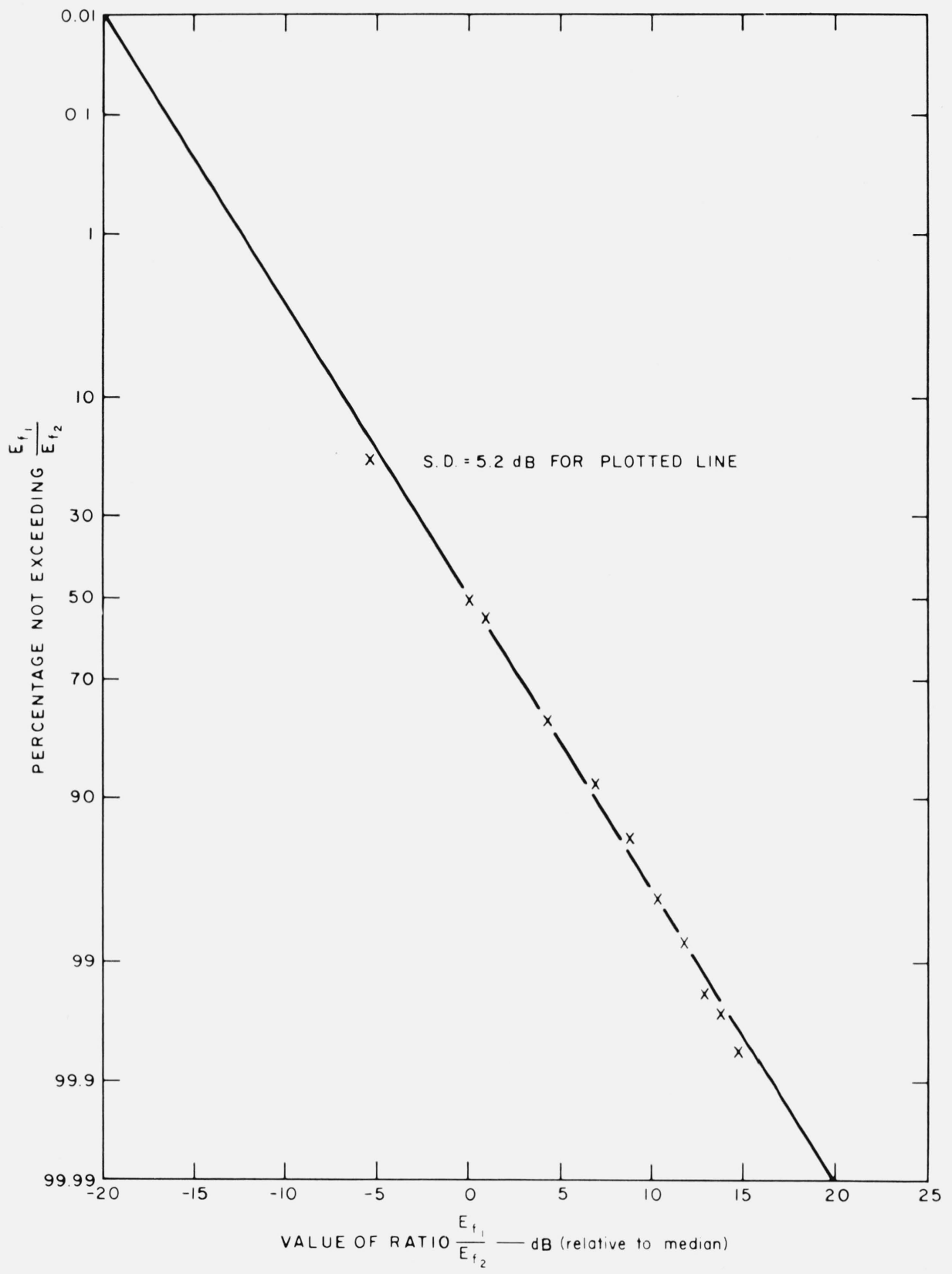

Figure 10. Amplitude distribution of ratio 18 to $10 \mathrm{kHz}$.

\section{Discussion and Summary}

In section 2, calculations on a semitheoretical basis were made and the amplitude spectra at 100 $\mathrm{km}$ deduced from the current surge information. In section 3 a comparable spectrum was derived from observations of atmospherics. For comparison, figure 11 shows the three theoretical curves ((a), (b), and (c)) obtained for a first stroke, a subsequent stroke, and a positive stroke, respectively; also given are the average obtained from the experimental atmospherics observations (curve (d)) and (3.2) (curve (e)) which has been shown in section 3 to be a good fit over the frequency range of 2 to $20 \mathrm{kHz}$ to the mean of most sets of experimental results and 


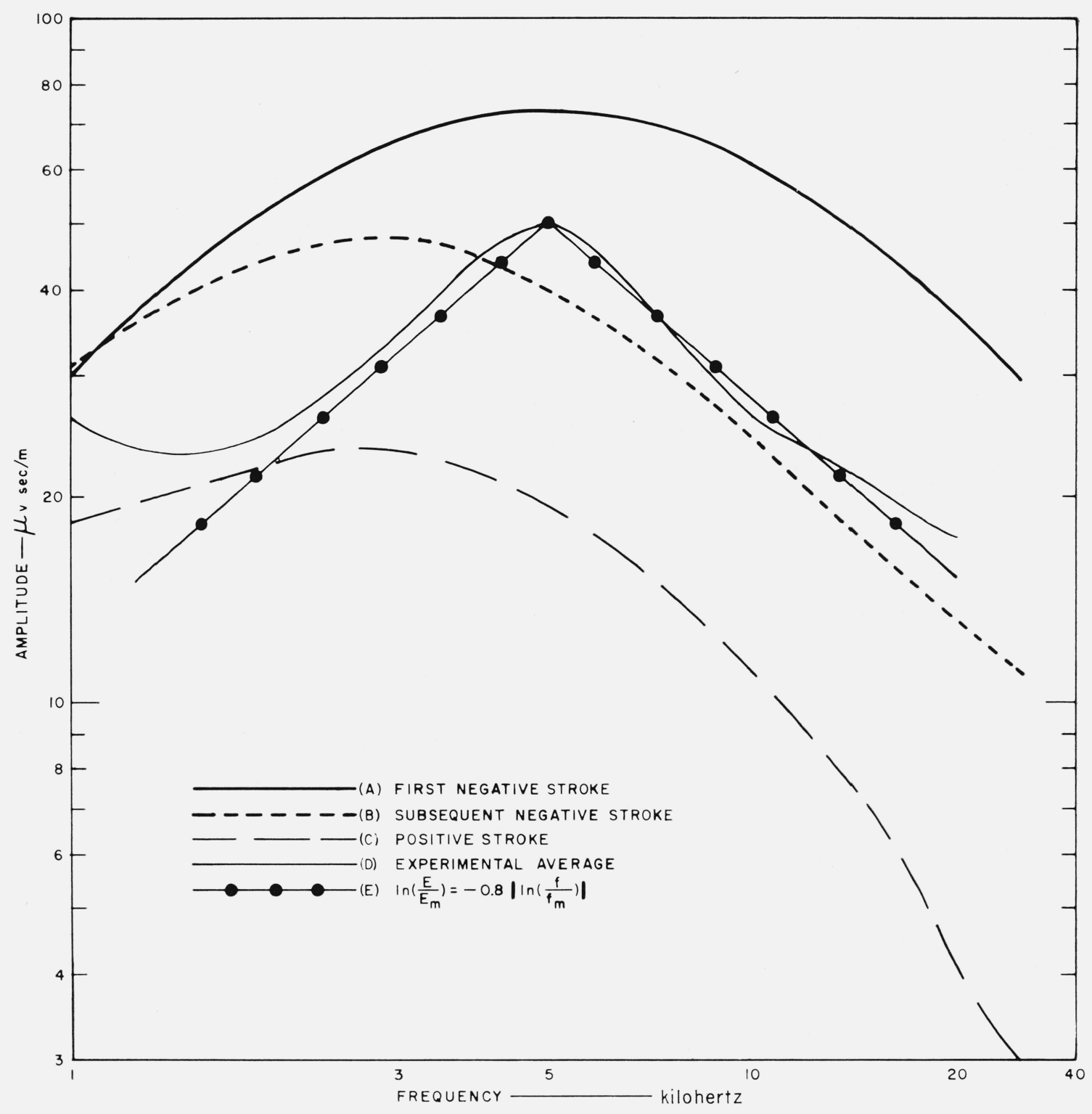

Figure 11. Summary of amplitude spectra at $100 \mathrm{~km}$.

which, with $E_{m}=50 \mu \mathrm{V}$ sec $/ \mathrm{m}$ and $f_{m}=5 \mathrm{kHz}$, is an excellent representation of the overall average.

The agreement in figure 11 between curves (a), (b), (d), and (e) is very good. The observation of atmospherics may be expected to sample both first and subsequent strokes; accordingly (d) should be intermediate between (a) and (b) both in amplitude and in the value of $f_{m}$. This is approximately what is found. Experimental data on positive strokes are not readily available, but by analogy with the negative strokes, curve (c) may be expected to be a good representation.

The consistency found between the theoretical approach and the spectrum obtained by extrapolation from atmospheries, with the amplitude adjusted ignoring the King's College results, is evidence for the belief advanced in section 3 that this school of workers overestimates the size of the average atmospheric. It is shown in appendix 1 how such overestimation can result from the selectivity intrinsic in the use of triggering methods; these methods can also lead to incorrect deductions regarding propagation even when only one waveguide mode of propagation is concerned.

The range of $f_{m}$ from the experimental observations was between 3 and $7 \mathrm{kHz}$. This is entirely in agreement with the variation shown in section 2 to result from changes in the parameters involved in the theoretical approach. An apparent paradox is that $f_{m}$ is less for subsequent strokes than for a first 


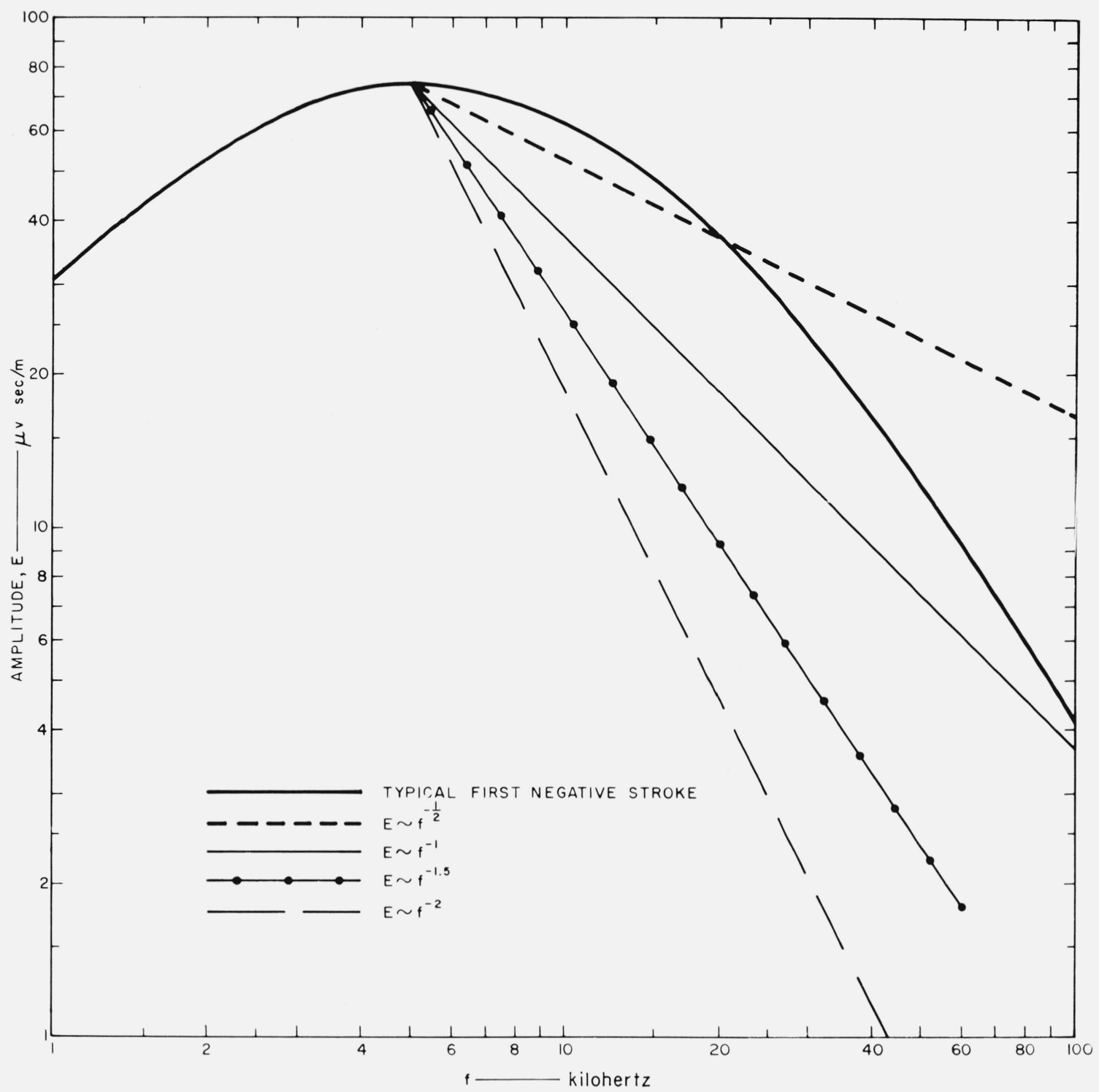

FIGURE 12. Variation of amplitude with frequency for $\mathrm{f}>\mathrm{f}_{\mathrm{m}}$.

return stroke, whereas the current surge is more sudden in the former case. The explanation of the paradox is, of course, that the length of channel as well as the current is involved in determining the radiated spectrum. In the limit, an infinitely rapid current pulse would not radiate any atmospheric, since the channel length (effective radiating antenna length) would be zero.

Amplitude variations obey a log-normal distributimon with a standard deviation of between 4 and 10 $\mathrm{dB} ; 7 \mathrm{~dB}$ is an average value. As regards spectral variations, beside the dissimilarities between groups, represented by an adjustment of $f_{m}$, considerable differences exist between separate atmospherics. Notably, the ratio of the amplitudes at two selected frequencies follows a log-normal distribution, with $\sigma=5 \mathrm{~dB}$. This kind of variation can be accounted for on the theoretical approach by changing the parameters and introducing subsidiary current surges. However, the data presently available are far too restricted to justify a treatment of these secondary influences with any degree of confidence.

The variation of amplitude with frequency for frequencies exceeding $f_{\mathrm{m}}$ has been a question given some attention in the past. Much effort has been devoted to fitting the variation to a law of the form $f^{-c}$ where $c$ is a constant. It is now becoming evident that a particular value of $c$ is only applicable over a limited range in frequency and that as this range increases so does $c$. For example, the experimental data of figure 8 give $c=0.8$ between 5 and $20 \mathrm{kHz}$; the results of Taylor [1963] show $c=1.0$ for the

791 
frequency range of 10 to $100 \mathrm{kHz}$ and somewhat less from 5 to $10 \mathrm{kHz}$; while Watt and Maxwell [1957] suggest $c=2$ between 40 and $80 \mathrm{kHz}$. The theoretical treatment also implies $c$ increasing with frequency. This is illustrated in figure 12 in which the spectrum of figure 11 for a typical first stroke is plotted on a log-log basis over the range from 1 to $100 \mathrm{kHz}$; for comparative purposes the lines corresponding to $c=0.5,1.0,1.5$, and 2.0 , and passing through the point $\left(E_{m}, f_{m}\right)$ are shown.

In conclusion it is perhaps appropriate to stress the dangers of extrapolating laws applying to the VLF range to higher frequency bands, particularly if the general radio noise from a thunderstorm and not that from particular types of atmospherics is being considered. Even for the return stroke the theoretical development of section 2 is very idealized: no account is taken, for example, of branching, a feature which may well be responsible for some of the spectral irregularities experimentally observed at LF [Taylor, 1963]. If the total noise generated by lightning at VLF and LF is being considered then obviously the disturbances due to the leader and to $K$ pulses, and discussed in the companion paper [Arnold and Pierce, 1964], should be included in addition to return-stroke atmospherics. Even so the description of the noise may not be complete: small sparks not considered in either of the two present papers are undoubtedly the dominant noise generators at HF [Pierce, 1962], and may also have some significance at lower frequencies. The ultimate limits in thunderstorm noise generators are the minute sparks associated with corona and other discharges from water drops [Pierce, 1962; Sartor, 1963]; this noise source may bear little relation to the actual occurrence of a lightning flash.

\section{Appendix 1}

Very-low-frequency atmospherics produced by leader pulses, by $K$ changes, and by return strokes in a given thunderstorm are necessarily recorded against a background of circuit noise, manmade interference, and interference from other storms occurring at the same time. To reduce such interference many recording devices utilize triggering mechanisms, so that only those atmospherics exceeding a predetermined threshold amplitude are recorded. This means that the mean intensity of the recorded strokes from distant storms, considered as a function of range, does not decrease as rapidly as the attenuation function, taken by itself, would indicate.

Section 3 indicates that the source amplitudes of individual atmospherics from a nearby storm follow a log-normal distribution. That is

$$
Q(E)=\frac{1}{\sigma \sqrt{2 \pi}} \int_{E}^{\infty} \exp \left[-\frac{\left(E-E_{\mathrm{med}}\right)^{2}}{2 \sigma^{2}}\right] d E
$$

where $E$ is the amplitude of an individual atmospheric expressed on a logarithmic scale; $E_{\text {med }}$ is the median amplitude; $Q(E)$ is the probability of an individual atmospheric exceeding amplitude $E$; and $\sigma$ is the standard deviation for the sample. Experimentally, $\sigma$ was found to be between 4 and $10 \mathrm{~dB}$.

Let the threshold of the detection device be $E_{0}$. The mean amplitude of the recorded atmospherics, measured with respect to the threshold, is

$$
\begin{aligned}
\bar{E}= & \left\{\frac{1}{\sigma \sqrt{2} \pi} \int_{E_{0}}^{\infty}\left(E-E_{0}\right) \exp \right. \\
= & \left\{\frac{1}{\sigma \sqrt{2} \pi} \int_{E_{0}}^{\infty}\left(E-E_{\mathrm{med}}\right) \exp \right. \\
& {\left.\left[\frac{-\left(E-E_{\mathrm{med}}\right)^{2}}{2 \sigma^{2}}\right] d E\right\} \div Q\left(E_{0}\right) } \\
& \left.\frac{\sigma}{\sqrt{2} \pi} \exp \left[\frac{-\left(E_{0}-E_{\mathrm{med}}\right)^{2}}{2 \sigma^{2}}\right]-\left(E_{0}-E_{\mathrm{med}}\right) Q\left(E_{0}\right)\right\} \div Q\left(E_{0}\right) \\
= & \frac{Q\left(E_{0}\right)}{\left.2-E_{\mathrm{med}}\right) .}
\end{aligned}
$$

This function is shown versus $\left(E_{0}-E_{\text {med }}\right)$ in figure 13, plotted in units of $\sigma$. For cases when practically all the atmospherics are recorded ( $E_{0}<<E_{\text {med }}$ ), raising the threshold by a given number of decibels reduces $\bar{E}$ by almost the same amount. As $E_{0}$ becomes larger than $E_{\text {med }}$, however, the change in $\bar{E}$ for a given change in $E_{0}$ (or $E_{\text {med }}$ ) becomes quite small.

It is necessary in analyzing the amplitude distribution of a sample of atmospherics to take into account the relationship between $E_{0}$ and $E_{\text {med }} ; E_{0}$ may be set to limit the number of strokes recorded or to avoid triggering by random noise. Circuit noise in the receiving equipment proves to be negligible, but manmade noise picked up by the antenna is significant in some areas, especially near large cities. A typical value for $E_{0}$ in the central London area, where much work on atmospherics has been done, is $2 \mu \mathrm{V} \mathrm{sec} / \mathrm{m}$ at $10 \mathrm{kHz}$. Comparing this with the field produced by a typical return stroke $100 \mathrm{~km}$ distant of, say, $50 \mu \mathrm{V}$ sec/m shows that even under such unfavorable conditions the signal-to-noise ratio for the median stroke is around 25 to $30 \mathrm{~dB}$ for a nearby storm. Taking $\sigma$, the standard deviation of $E$, as $7 \mathrm{~dB}$, it is seen that the proportion of strokes masked by noise is completely negligible, being of the order of $10^{-5}$.

Severe manmade interference can distort observations on distant storms. The effect of attenuation is to shift $E_{\text {med }}$ down, with $\sigma$ remaining the same. The attenuation in decibels at $10 \mathrm{kHz}$ is given approximately by $\left[10 \log d+(2.5) 10^{-3} \times d\right]$ where $d$ is the distance in $\mathrm{km}$. At $3000 \mathrm{~km}$, an atmospheric is reduced in amplitude $22 \mathrm{~dB}$ below its amplitude at $100 \mathrm{~km}$. This implies a signal-to-noise ratio near one for a median stroke recorded at $3000 \mathrm{~km}$ in a noisy area, with half of the strokes not recorded. This situation corresponds to the region near $\left(E_{0}-E_{\mathrm{med}}\right)=0$ on figure 13 ; some distortion in 


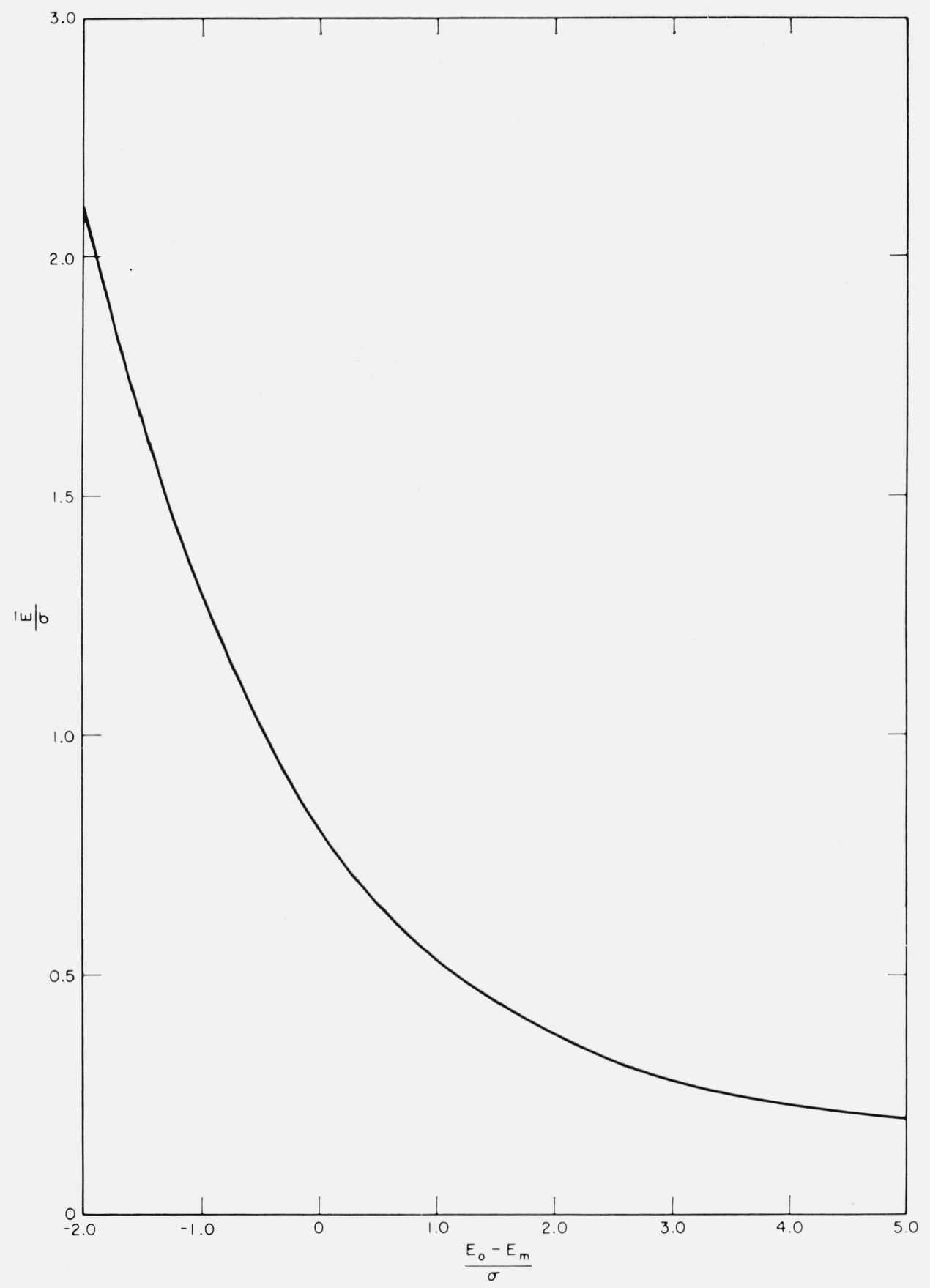

Figure 13. $\overline{\mathrm{E}}$ as a function of threshold setting.

experimental determination of $\bar{E}$ is to be expected in such a case.

In practice, the tendency in recording atmospherics is to set $E_{0}$ high enough so that only well-defined waveforms are recorded. Since these must stand out, not only against any manmade noise that may be present but also against a persistent background of weaker or more distant atmospherics, only the strongest atmospherics are recorded. For example, some studies in Great Britain have been limited to the atmospherics strong enough to be located by the Meteorological Sferics Network [Ockenden, 1947]. Such records can yield considerable information, but the limitations implicit in triggering methods must be borne in mind.

The use of such sampling techniques necessarily involves working in a region toward the right side of figure 13 , that is, with $\left(E_{0}-E_{\text {med }}\right)$ being equal to 
$2 \sigma$ to $3 \sigma$. In this case, there is little variation in $\bar{E}$ with changes in $E_{0}$ or $E_{\text {med. }}$. Therefore, $\bar{E}$ is a very slowly varying function of $d$, and sampling errors will largely determine which of two distant storms yields a greater value of $\bar{E}$. This is a plausible explanation for the apparently negative attenuation coefficients that have been reported by some researchers.

We are grateful for the use of data unpublished in the open literature but contained in the theses of Dr. B. J. Steptoe, Dr. J. Chapman, Dr. D. L. Croom, and Dr. J. C. Williams.

The research described in this paper summarizes some of the work discussed in greater detail in a report by Pierce, Arnold, and Dennis [1962]. This report was prepared under U.S. Air Force Contract AF33 (657)-7009; it is a pleasure to acknowledge the action of the Air Force authorities in permitting publication.

\section{References}

Arnold, H. R., and E. T. Pierce (July 1964), Leader and junction processes in the lightning discharge as a source of VLF atmospheries, J. Res. NBS/USNC-URSI 68D (Radio Sci.), No. 7.

Barlow, J. S., G. W. Frey, Jr., and J. B. Newman (1954), Very low frequency noise power from the lightning discharge. J. Franklin Inst $2 \boldsymbol{\gamma}, 145-163$.

Berger, K. (1961), Gewitterforschung auf dem monte San Salvatore, ETZ A82, 249-260.

Berger, K. (1962), private communication.

Bowe, P. W. A. (1951), The waveforms of atmospherics and the propagation of very low frequency radio waves, Phil. Mag. 42, 121-138.

Bruce, C. E. R., and R. H. Golde (1941), The lightning discharge, JIEE (London) 88(II), 487-505.

Chapman, J. (1955), The waveforms of atmospherics and the propagation of very low frequency radio waves, Ph. D. thesis, University of Cambridge, England.
Chapman, F. W., and W. D. Matthews (1953), Audiofrequency spectrum of atmospherics, Nature 172, 495-497.

Croom, D. L. (1961), The spectra of atmospherics and the propagation of very low frequency radio waves, $\mathrm{Ph}$. D. thesis, University of Cambridge, England.

Edwards, A. G. (1956), The effect of atmospheries on tuned circuits, J. Brit. IRE 16, 31 .

Hefley, G., R. H. Doherty, and R. L. Linfield (1959), private communication.

Horner, F. (1960), The design and use of instruments for counting local lightning flashes, Proc, IEE (London) 10\%B, 321-330.

Horner, F. (1961), Narrow band atmospherics from two local thunderstorms, J. Atmospheric Terrest. Phys. 21, $13-25$.

Lejay, P. (1926), Les perturbations orageuses du champ électrique et leur propagation à grande distance, Thesis, Université de Paris, France.

Ockenden, C. N. (1947), Sferics, Met, Mag. 76, 78-86.

Pierce, E. T. (1950), Disturbances of the earth's field due to lightning discharges, Ph.D. thesis, University of Cambridge, England.

Pierce, E. T. (1960), Atmospherics from lightning flashes with multiple strokes, J. Geophys, Res. 65, 1867-1871.

Pierce, E. T. (1962), Meteorological aspects of the sources of atmospherics noise in lightning, paper in Radio Noise of Terrestrial Origin, ed. F. Horner, Elsevier, 55-71.

Sartor, J. D. (1963), Radio emission from clouds, J. Geophys. Res. 68, 5169-5172.

Schönland, B. F. J. (1956), The lightning discharge, Handbuch der Physik 22, 576-628.

Steptoe, B. J. (1958), Some observations on the spectrum and propagation of atmospherics, Ph.D. thesis, University of London, England.

Taylor, W. L. (1963), Radiation field characteristics of lightning discharges in the band $1 \mathrm{kc} / \mathrm{s}$ to $100 \mathrm{kc} / \mathrm{s}, \mathrm{J}$. Res. NBS 67D (Radio Prop.), No. 5, 539-550.

Tavlor, W. L., and A. G. Jean (1959), Very low frequenev radiation spectra of lightning discharges, J. Res. NBS 63D, (Radio Prop.), No 2, 199-204.

Wagner, C. F., and G. D. McCann (1950), Lightning phenomena, Westinghouse Electrical Transmission and Distribution Reference Book, 4th ed., 542-577.

Watt, A. D., and E. L. Maxwell (1957), Characteristics of atmospheric noise from 1 to $100 \mathrm{kc}$, Proc. IRE 45, 787-794.

Williams, J. C. (1959), Thunderstorms and VLF radio noise, Ph.D. thesis, Harvard University, Cambridge, Mass.

(Paper 68D7-375) 